\title{
Association of primary care physicians' exercise habits and their age, specialty, and workplace
}

\author{
This article was published in the following Dove Press journal: \\ Journal of Multidisciplinary Healthcare \\ 6 November 2013 \\ Number of times this article has been viewed
}

\section{Yoshiyuki Morishita' \\ Atushi Miki \\ Mari Okada' \\ Satoshi Tsuboi \\ Kenichi Ishibashi ${ }^{3}$ \\ Yasuhiro Ando' \\ Eiji Kusano ${ }^{4}$}

'Division of Nephrology, Department of Medicine, ${ }^{2}$ Department of Public Health, Jichi Medical University, Tochigi, ${ }^{3}$ Department of Medical Physiology, Meiji Pharmaceutical University, Tokyo, ${ }^{4}$ Utsunomiya Social Insurance Hospital, Tochigi, Japan
Correspondence: Yoshiyuki Morishita Division of Nephrology, Department of Medicine, Jichi Medical University, 33I I-I, Yakushiji, Shimotsuke City, Tochigi 329-0498, Japan

Tel +81285587346

Fax +81285444869

Email ymori@jichi.ac.jp
Background: In this study, we investigated primary care physicians' exercise habits, and the association of this variable with their age, specialty, and workplace.

Methods: The population of this cross-sectional study comprised 3,310 medical doctors who graduated from Jichi Medical University in Japan between 1978 and 2012. The study instrument was a self-administered questionnaire mailed in August 2012 to investigate primary care physicians' exercise habits, age, specialty, and workplace.

Results: The 896 available primary care physicians' responses to the self-administered questionnaire were analyzed. Their exercise frequency was as follows: daily, 104 (11.6\%); at least 2-3 times per week, 235 (26.2\%); no more than once a week, 225 (25.1\%); no more than once a month, 278 (31.0\%); and other, $52(5.8 \%)$. Their exercise intensity was as follows: high ( $\geq 6$ Mets), 264 (29.5\%); moderate (4-6 Mets), 199 (22.2\%); mild, (3-4 Mets), 295 (32.9\%); very mild (<3 Mets), 68 (7.6\%); none, 64 (7.1\%); and other, $6(0.7 \%)$. Their exercise volume was calculated to represent their exercise habits by multiplying score for exercise frequency by score for intensity. Multivariate linear regression analyses showed that the primary care physicians' exercise volumes were associated with their age $(P<0.01)$ and workplace $(P<0.01)$, but not with their specialty $(P=0.37)$. Primary care physicians in the older age group were more likely to have a higher exercise volume than those in the younger age groups (50-60 years $>$ older than 60 years $>40-50$ years $>30-40$ years $>24-30$ years). Primary care physicians working in a clinic were more likely to have a higher exercise volume than those working in a university hospital, polyclinic hospital, or hospital.

Conclusion: Primary care physicians' exercise habits were associated with their age and workplace, but not with their specialty.

Keywords: primary care physician, self-administered questionnaire, exercise habits, age, specialty, workplace

\section{Introduction}

Exercise has a positive impact on total morbidity and mortality, and can also prevent many chronic diseases, such as cardiovascular disease, metabolic disease, chronic kidney disease, arthritis, obesity, and depression. ${ }^{1-8}$ Several exercise guidelines recommend at least 2.5 hours of exercise per week. ${ }^{9-14}$ Primary care physicians have an important role in exercise counseling because they manage patients at the front line. Exercise counseling by primary care physicians has been reported to improve patients' exercise habits. ${ }^{15}$ Several studies have also reported that primary care physicians' own lifestyles may influence the lifestyle counseling that they offer to patients. ${ }^{16-19}$ These lines of evidence suggest that primary care physicians' exercise habits are important for both their own health and when counseling patients about exercise. 
However, details concerning the exercise habits of primary care physicians have not been previously reported. Therefore, we tried to clarify whether primary care physicians take good care of themselves by exercising. In addition, given that primary care physicians vary with regard to age, specialty, and workplace, we investigated the relationship between exercise habits and age, specialty, and workplace in a large population $(n=3,310)$ of medical doctors.

\section{Subjects and methods}

This cross-sectional study was conducted in accordance with the Declaration of Helsinki and was approved by a member of the ethics committee of Jichi Medical University.

\section{Subjects}

The study population comprised 3,310 medical doctors who graduated from Jichi Medical University in Japan between 1978 and 2012. Medical doctors who graduate from this university have a 5-7-year obligation to work in a rural area of Japan as primary care physicians. Most ( $>80 \%)$ continue to work as primary care physicians after this term of duty.

\section{Study instrument}

The study instrument was a self-administered questionnaire designed to obtain detailed information about specific characteristics of primary care physicians, including their age, specialty, workplace, personal exercise habits, exercise counseling for patients with metabolic syndrome and cardiovascular disease, and management of chronic kidney disease (exercise counseling practice, medical prescription pattern). The results concerning their exercise counseling of patients with metabolic syndrome and/or cardiovascular disease and management of chronic kidney disease will be analyzed and reported elsewhere. The parameters canvassed in the questionnaire along with the response options were as follows:

1. Age (24-30, 30-40, 40-50, 50-60, or $\geq 60$ years)

2. Specialty (internal medicine, surgery, general medicine, pediatrics, other)

3. Workplace (university hospital, polyclinic hospital, hospital, clinic, other [including health facilities for recuperation])

4. Weekly frequency of exercise sessions lasting 30 minutes (daily, at least 2-3 times per week, no more than once a week, no more than once a month, other)

5. Intensity of exercise (high [ $\geq 6$ Mets], eg, swimming, jogging, soccer, cycling; moderate [4-6 Mets], eg, quick walking, golf; mild [3-4 Mets], eg, walking, cleaning; very mild [ $<3$ Mets], eg, stretching, cooking; none; other).

\section{Exercise volume}

Exercise volume was calculated to represent exercise habits by multiplying the score for exercise frequency by the score for exercise intensity. The frequency of exercise sessions lasting at least 30 minutes was scored as follows: daily, 3.5 ( 7 days $\times 0.5$ hours); at least $2-3$ times/week, 1.25 (2.5 days $\times 0.5$ hours); no more than once a week 0.5 (one day $\times 0.5$ hours), no more than once a month, or 0.125 ( 0.25 days $\times 0.5$ hours $)$. Exercise intensity was scored as follows: high, 6 (6 Mets); moderate, 5 (5 Mets); mild, 4 (4 Mets); very mild, 3 (3 Mets); or none, 0 (0 Mets). Answers marked "other" for exercise frequency $(n=52)$ and exercise intensity $(n=6)$ were excluded from evaluation of exercise volume because they could not be scored.

\section{Statistical analysis}

All data are expressed as the mean \pm standard deviation. The associations between primary care physicians' exercise volume and their age, specialty, and workplace were analyzed by multiple linear regression analysis to determine the independent variables. SPSS Statistics version 21 software (IBM, Armonk, NY, USA) was used for the statistical analysis. Values of $P<0.05$ were considered to be statistically significant.

\section{Results}

The survey was mailed to 3,310 medical doctors, with responses received from $933(28.2 \%)$. Thirty-seven responses were excluded for lack of completeness in terms of information supplied regarding age group, specialty, and workplace. The remaining 896 responses to the self-administered questionnaire were analyzed. As shown in Table 1, the primary care physicians' age, specialty, and workplace data were as follows:

1. Age (24-30 years, 75 [8.4\%]; 30-40 years, 273 [30.5\%]; 40-50 years, 284 [31.7\%]; 50-60 years, 249 [27.8\%]; and $\geq 60$ years, $15[1.7 \%])$

2. Specialty (internal medicine, 412 [46.0\%]; surgery, 168 [18.8\%]; general medicine, 163 [18.2\%]; pediatrics, 45 [5.0\%]; other, 108 [12.1\%])

3. Workplace (university hospital, 108 [12.1\%]; polyclinic hospital, 201 [22.4\%]; hospital, 256 [28.6\%]; clinic, 288 [32.1\%]; other, 43 [4.8\%]). 
Table I Characteristics of primary care physicians

\begin{tabular}{ll}
\hline & $\mathbf{n}(\%)$ \\
\hline Age, years & $75(8.4)$ \\
$24-30$ & $273(30.5)$ \\
$30-40$ & $284(31.7)$ \\
$40-50$ & $249(27.8)$ \\
$50-60$ & $15(1.7)$ \\
$\geq 60$ & $896(100)$ \\
Total & \\
Specialty & $412(46.0)$ \\
Internal medicine & $168(18.8)$ \\
Surgery & $163(18.2)$ \\
General medicine & $45(5.0)$ \\
Pediatrics & $108(12.1)$ \\
Other & $896(100)$ \\
Total & \\
Workplace & $108(12.1)$ \\
University hospital & $201(22.4)$ \\
Polyclinic hospital & $256(28.6)$ \\
Hospital & $288(32.1)$ \\
Clinic & $43(4.8)$ \\
Other & $896(100)$ \\
Total &
\end{tabular}

\section{Primary care physicians' exercise habits}

The primary care physicians' exercise frequency was as follows: daily, 104 (11.6\%); at least 2-3 times per week, 235 (26.2\%); at least once a week, $225(25.1 \%)$; no more than once a month, 278 (31.0\%); or other, 52 (5.8\%, Table 2). Their exercise intensity was as follows: high ( $\geq 6$ Mets), 264 (29.5\%); moderate (4-6 Mets), 199 (22.2\%); mild (3-4 Mets), 295 (32.9\%); very mild ( $<3$ Mets) $68(7.6 \%)$; none, $64(7.1 \%)$; or other, $6(0.7 \%$, Table 2). Exercise frequency and intensity categorized by age,

Table 2 Primary care physicians' own exercise habits

\begin{tabular}{ll}
\hline & $\mathbf{n}(\%)$ \\
\hline Frequency & \\
Daily & $104(11.6)$ \\
At least 2-3 times per week & $235(26.2)$ \\
No more than once per week & $225(25.1)$ \\
No more than once a month & $278(31.0)$ \\
Other & $52(5.8)$ \\
N/A & $2(0.2)$ \\
Total & $896(100)$ \\
Intensity & \\
High ( $\geq 6$ Mets) & $264(29.5)$ \\
Moderate (4-6 Mets) & $199(22.2)$ \\
Mild (3-4 Mets) & $295(32.9)$ \\
Very mild (<3 Mets) & $68(7.6)$ \\
None & $64(7.1)$ \\
Other & $6(0.7)$ \\
Total & $896(100)$ \\
\hline
\end{tabular}

Abbreviation: N/A, not available. specialty, and workplace are shown in Figure 1A and B. Mean exercise volume categorized by age, specialty, and workplace was as follows:

1. Age (24-30 years, $3.12 \pm 3.88 ; 30-40$ years, $3.65 \pm 4.78$; $40-50$ years, $5.12 \pm 5.84$; 50-60 years, $6.43 \pm 6.42$; and $\geq 60$ years, $5.03 \pm 4.43$ )

2. Specialty (internal medicine, $4.42 \pm 5.41$; surgery, $4.67 \pm 5.56$; general medicine, $5.75 \pm 6.06$; pediatrics, $4.90 \pm 6.21$; or other, $5.39 \pm 5.75$ )

3. Workplace (university hospital, $4.14 \pm 4.90$; polyclinic hospital, $3.86 \pm 4.99$; hospital, $4.21 \pm 4.90$; clinic, $6.29 \pm 6.64$; and other, $4.85 \pm 5.66$ ).

Multivariate linear regression analyses showed that the primary care physicians' age $(P<0.01)$ and workplace $(P<0.01)$ were associated with their exercise volume (Table 3 and Figure 1C). However, their specialty was not associated with their exercise volume $(P=0.37$, Table 3 and Figure 1C). Primary care physicians in the older age group were more likely to have a higher exercise volume than their younger counterparts (50-60 years $>$ older than 60 years $>40-50$ years $>30-40$ years $>24-30$ years). Primary care physicians working in a clinic were more likely to have a higher exercise volume than those working in a university hospital, polyclinic hospital, or hospital.

\section{Discussion}

In the present study, the exercise habits of primary care physicians were significantly associated with their age and workplace, but not with their specialty. Their age group was positively associated with their exercise habits. Those in the older age group were likely to do more exercise than those in the younger age groups (50-60 years $>$ older than 60 years $>40-50$ years $>30-40$ years $>24-30$ years). Primary care physicians working in a clinic were more likely to have better exercise habits than those working in a university hospital, polyclinic hospital, or hospital. These results may be explained by primary care physicians in the older age groups and those working in clinics taking better care of their own health and being able to make time available for exercise than younger doctors working in a university hospital, polyclinic hospital, or hospital. Many physical activity guidelines include recommendations regarding exercise. ${ }^{9-14}$ US physical activity guidelines recommend at least 2.5 hours a week of moderate intensity physical activity, such as brisk walking. ${ }^{9}$ The UK physical activity guidelines also recommend at least 2.5 hours of moderate intensity activity in bouts of 10 minutes or more. ${ }^{14}$ The 
A
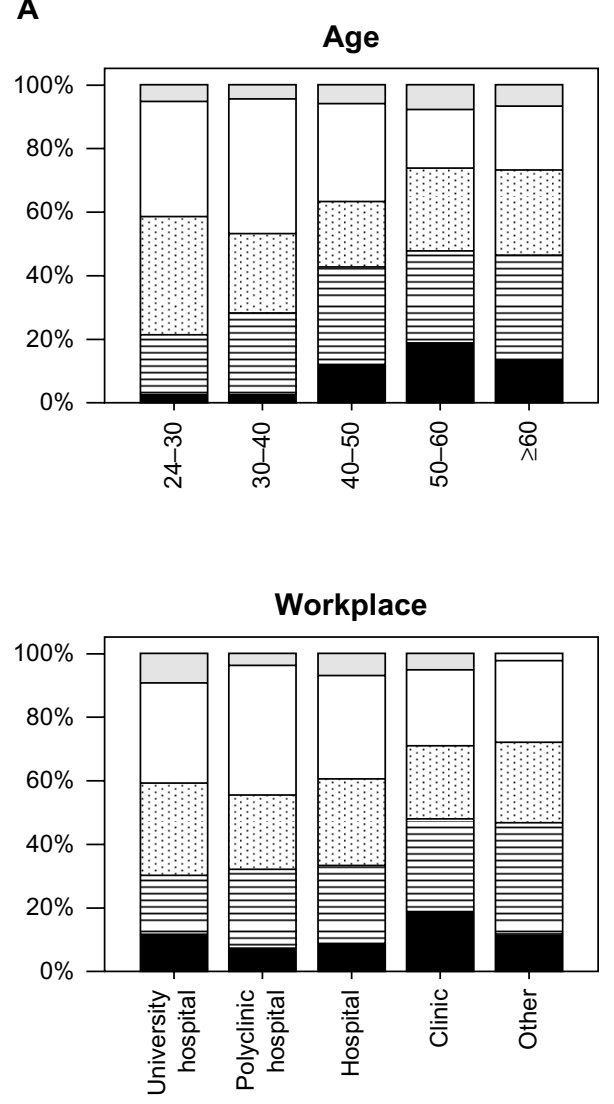

B
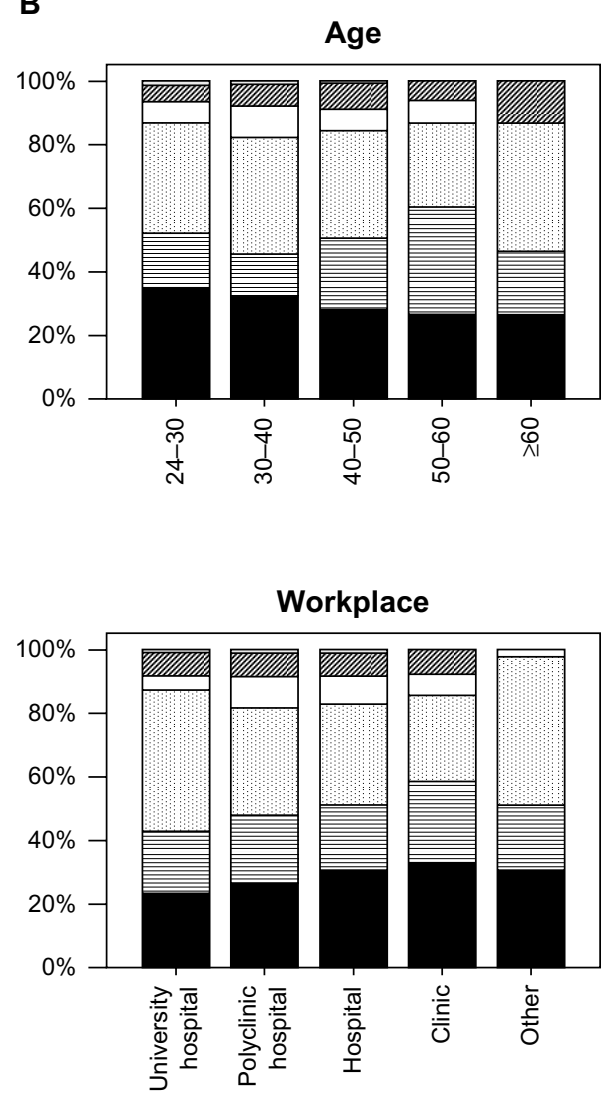

Specialty
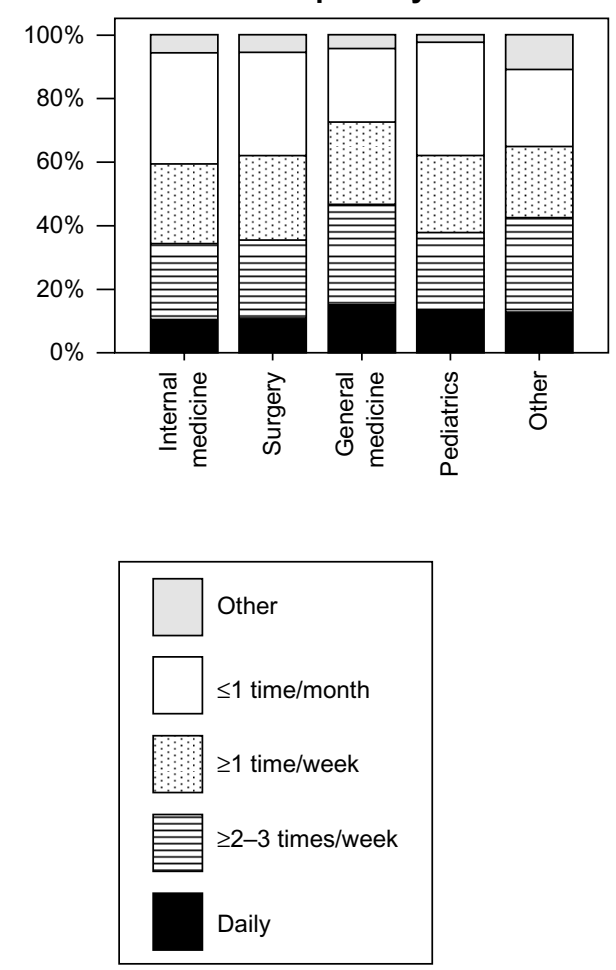

Specialty

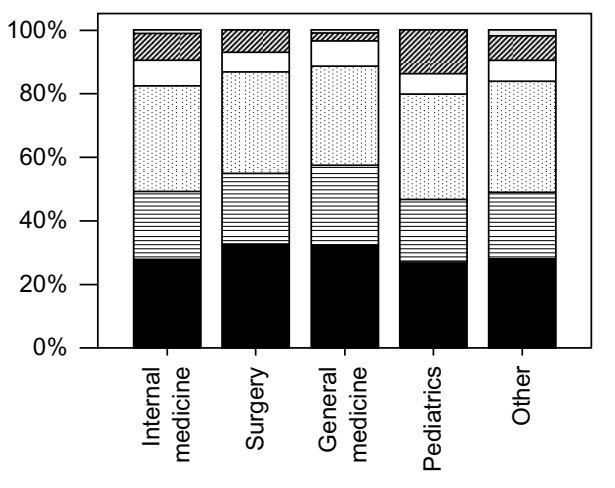

Figure I (Continued) 

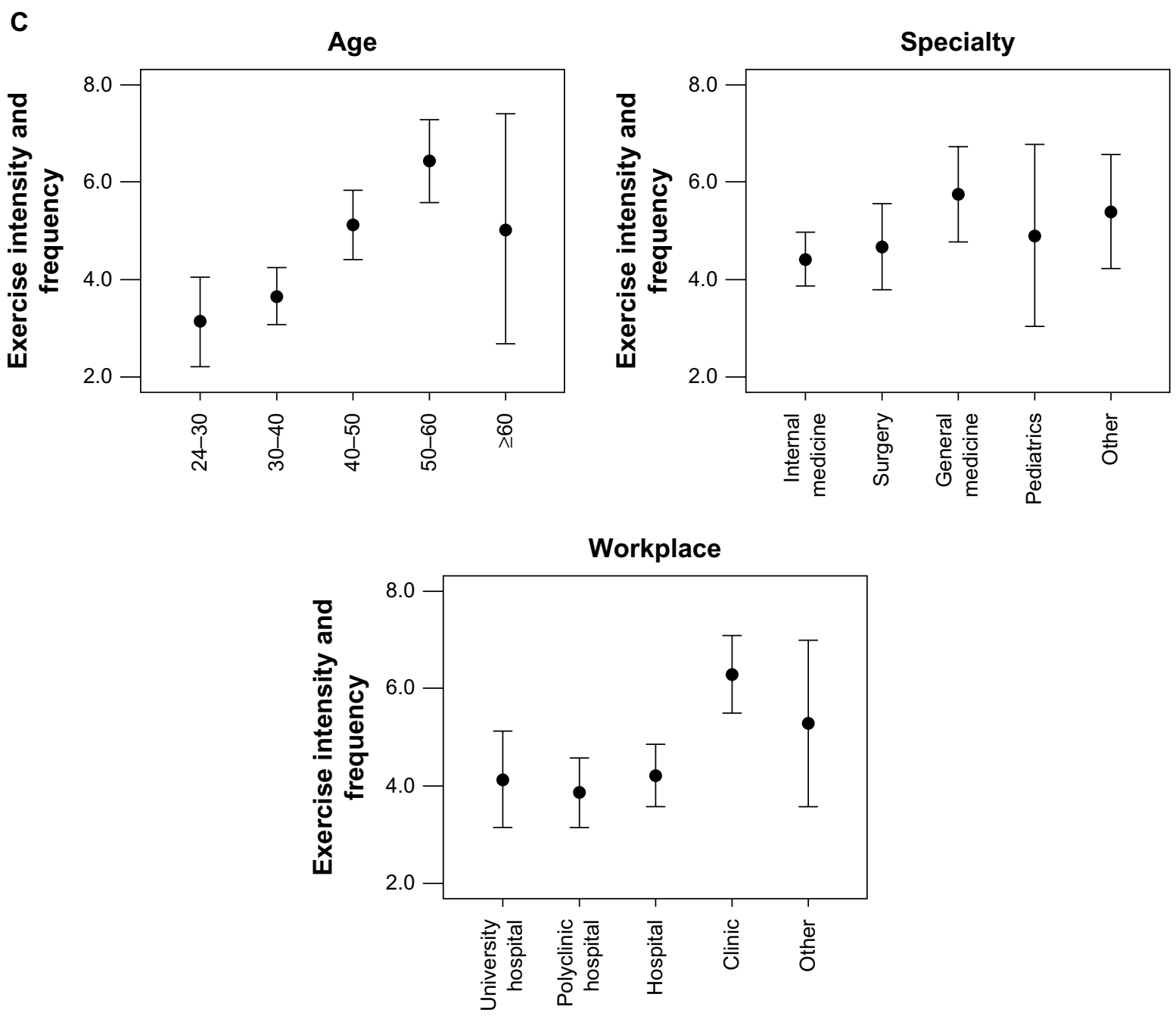

Figure I (A) Associations of primary care physicians' exercise frequency and their age, specialty, and workplace. (B) Asociations of primary care physicians' exercise intensity and their age, specialty, and workplace. (C) Associations of primary care physicians' exercise volume and their age, specialty, and workplace.

committee of Ministry of Health, Labour and welfare of Japan recommends 23 Mets-hours (Mets multiple hours) per week of exercise with an intensity $>3$ Mets. ${ }^{12}$ The exercise frequency of many primary care physicians in the present study did not reach the recommended levels; about $50 \%$ of the respondents reported an exercise frequency of less than once a week (no more than once a week, 25.1\%; no more than once a month, $31.0 \%)$. Their exercise intensity likely

Table 3 Multivariate linear regression analyses of the association between primary care physicians' own exercise habits (exercise volume) and their age, specialty, and workplace

\begin{tabular}{lll}
\hline & $\left(\right.$ Model $\boldsymbol{R}^{2}=\mathbf{0 . 0 5 6 )}$ & \\
\cline { 2 - 3 } & $\boldsymbol{\beta}$ & $\boldsymbol{P}$ \\
\hline Age & 0.18 & $<0.01$ \\
Specialty & 0.07 & 0.37 \\
Workplace & 0.10 & $<0.01$ \\
\hline
\end{tabular}

reached the recommended levels because over $80 \%$ of primary care physicians reported an exercise intensity above 3 Mets ( $\geq 6$ Mets, 29.5\%; 4-6 Mets, 22.2\%; 3-4 Mets, 32.9\%). Several studies have reported that physicians' lifestyles may influence the lifestyle counseling they offer to patients. ${ }^{16-19}$ Kawakami et al reported that physicians who smoked themselves were less likely to recommend that patients stop smoking than those who did not smoke. ${ }^{17}$ Abramson et al reported that physicians who exercised regularly were more likely to counsel their patients on the benefits of exercise. ${ }^{16}$ These lines of evidence suggest that improvement of lifestyle, including exercise habits, may contribute positively to not only primary care physicians' own health but also their health counseling of patients. Therefore, encouragement of primary care physicians to undertake exercise seems to be important for public health. Considering that the level of exercise performed by primary care physicians in the 
present study did not reach that recommended in the current exercise guidelines, greater encouragement of doctors to exercise is necessary.

There are several limitations in this study. First, the study instrument was a mailed self-administered questionnaire, which raises the issue of self-selection bias and could also have contributed to the low response rate $(28.2 \%)$. Second, the primary care physicians in this study may not be representative of the entire population of primary care physicians, because all had graduated from the same university. Third, it should be noted that the results of this study were from a self-administered questionnaire, and therefore do not reflect an objective evaluation of primary care physicians' actual exercise habits. Finally, primary care physicians' reports of their own behavior may not always be accurate. ${ }^{20}$ Further studies will be needed to investigate the actual exercise habits of primary care physicians using instruments such as exercise recording devices.

In conclusion, primary care physicians' exercise habits were found to be inadequate in this study, and were significantly associated with age and workplace, but not with specialty.

\section{Acknowledgment}

The authors thank Minami Watanabe, Yuko Suda, Yukari Hoshino, and Aiko Oashi for their assistance with this research.

\section{Disclosure}

The authors report no conflicts of interest in this work.

\section{References}

1. Blair SN, Kampert JB, Kohl HW 3rd, et al. Influences of cardiorespiratory fitness and other precursors on cardiovascular disease and all-cause mortality in men and women. JAMA. 1996;276(3):205-210.

2. Boyden TW, Pamenter RW, Going SB, et al. Resistance exercise training is associated with decreases in serum low-density lipoprotein cholesterol levels in premenopausal women. Arch Intern Med. 1993;153(1): 97-100.
3. Clyne N. The importance of exercise training in predialysis patients with chronic kidney disease. Clin Nephrol. 2004;61 Suppl 1:S10-S13.

4. Goldberg L, Elliot DL. The effect of physical activity on lipid and lipoprotein levels. Med Clin North Am. 1985;69(1):41-55.

5. Kriska AM, Blair SN, Pereira MA. The potential role of physical activity in the prevention of non-insulin-dependent diabetes mellitus: the epidemiological evidence. Exerc Sport Sci Rev. 1994;22:121-143.

6. Underwood FB, Laughlin MH, Sturek M. Altered control of calcium in coronary smooth muscle cells by exercise training. Med Sci Sports Exerc. 1994;26(10):1230-1238.

7. Paffenbarger RS Jr, Lee IM, Leung R. Physical activity and personal characteristics associated with depression and suicide in American college men. Acta Psychiatr Scand Suppl. 1994;377:16-22.

8. Paffenbarger RS Jr, Hyde RT, Wing AL, Hsieh CC. Physical activity, all-cause mortality, and longevity of college alumni. $N$ Engl J Med. 1986;314(10):605-613.

9. [No authors listed]. Physical activity guidelines for Americans. Okla Nurse. 2008;53(4):25.

10. [No authors listed]. Abstracts of the 2005 Australian Conference of Science and Medicine in Sport, 5th National Physical Activity Conference, 4th National Sports Injury Prevention Conference. $J$ Sci Med Sport. 2005;8 Suppl 4:11-244.

11. Tremblay MS, Warburton DE, Janssen I, et al. New Canadian physical activity guidelines. Appl Physiol Nutr Metab. 2011;36(1):36-46.

12. Kawakubo K. [Physical activity and healthy Japan 21.] Nihon Rinsho. 2000;58 Suppl:532-537. Japanese.

13. Misra A, Nigam $P$, Hills AP, et al. Consensus physical activity guidelines for Asian Indians. Diabetes Technol Ther. 2012;14(1):83-98.

14. Dunlop M, Murray AD. Major limitations in knowledge of physical activity guidelines among UK medical students revealed: implications for the undergraduate medical curriculum. Br J Sports Med. 2013;47(11):718-720.

15. Logsdon DN, Lazaro CM, Meier RV. The feasibility of behavioral risk reduction in primary medical care. Am J Prev Med. 1989;5(5): 249-256.

16. Abramson S, Stein J, Schaufele M, Frates E, Rogan S. Personal exercise habits and counseling practices of primary care physicians: a national survey. Clin J Sport Med. 2000;10(1):40-48.

17. Kawakami M, Nakamura S, Fumimoto H, Takizawa J, Baba M. Relation between smoking status of physicians and their enthusiasm to offer smoking cessation advice. Intern Med. 1997;36(3):162-165.

18. Sherman SE, Hershman WY. Exercise counseling: how do general internists do? J Gen Intern Med. 1993;8(5):243-248.

19. Wells KB, Lewis CE, Leake B, Ware JE Jr. Do physicians preach what they practice? A study of physicians' health habits and counseling practices. JAMA. 1984;252(20):2846-2848.

20. McPhee SJ, Richard RJ, Solkowitz SN. Performance of cancer screening in a university general internal medicine practice: comparison with the 1980 American Cancer Society guidelines. J Gen Intern Med. 1986;1(5):275-281.
Journal of Multidisciplinary Healthcare

\section{Publish your work in this journal}

The Journal of Multidisciplinary Healthcare is an international, peerreviewed open-access journal that aims to represent and publish research in healthcare areas delivered by practitioners of different disciplines. This includes studies and reviews conducted by multidisciplinary teams as well as research which evaluates the results or conduct of such teams or health-

\section{Dovepress}

care processes in general. The journal covers a wide range of areas and welcomes submission from practitioners at all levels, from all over the world. The manuscript management system is completely online and includes a very quick and fair peer-review system. Visit http://www.dovepress. com/testimonials.php to read real quotes from published authors. 